\title{
INVESTIGATION OF DEFORMATION MECHANISMS IN TEXTURED MAGNESIUM ALLOY
}

\author{
Jan DITTRICH ${ }^{1 a}$, Jan ČAPEK ${ }^{1,2 b}$, Michal KNAPEK ${ }^{1,3 c}$, Peter MINÁRIK ${ }^{1 d}$ \\ ${ }^{1}$ Department of Physics of Materials, Charles University, Prague, Czech Republic, EU \\ ${ }^{2}$ Laboratory for Neutron Scattering and Imaging, Paul Scherrer Institute, Villigen, Switzerland \\ ${ }^{3}$ Nuclear Physics Institute, The Czech Academy of Sciences, Řež, Czech Republic, EU \\ adittrich.jan.cz@gmail.com, ${ }^{b j a n . c a p e k 89 @ g m a i l . c o m, ~}{ }^{c k}$ knapek@karlov.mff.cuni.cz, \\ dpeter.minarik@mff.cuni.cz
}

https://doi.org/10.37904/metal.2019.755

\begin{abstract}
Advanced in-situ and ex-situ methods were used to reveal active deformation mechanisms during deformation of magnesium alloy with a strong texture. Three sets of samples were prepared from the rolled sheet of commercial AZ31 alloy with respect to its strong basal texture - normal direction (ND), rolling direction (RD) and $45^{\circ}$ between RD and ND, and were deformed in both compression and tension. The signal of acoustic emission (AE) was measured concurrently during the deformation. Electron backscattered diffraction (EBSD) was used to study the microstructure after the selected stages of the deformation. It is shown that the extension twinning played an important role during the plastic deformation in the samples having favorably oriented basal texture component, whereas in the unfavorably oriented samples, the role of twinning was marginal. Pronounced activation of twinning only in some samples caused a considerable variation in the deformation behavior and $A E$ response. A consistent link between the energy and amplitudes of the $A E$ signal and the microstructure changes investigated by EBSD was established.
\end{abstract}

Keywords: Magnesium, deformation, twinning, acoustic emission, EBSD

\section{INTRODUCTION}

Magnesium and its alloys have been in the focus of many studies in recent decades. The reason for this interest is the very low density of magnesium alloys, making it the lightest (i.e. of the lowest density) currently used structural metals. By alloying magnesium, many of the drawbacks of the pure metal can be reduced or eliminated altogether (e.g. mechanical properties and corrosion resistance), resulting in a structural metal with a high potential [1,2]. The deformation behavior of magnesium and its alloy is rather complex due to its hexagonal close-packed structure, requiring the concurrent activity of multiple deformation mechanisms in order to achieve homogenous deformation. The activity of individual deformation mechanisms depends significantly on the texture, used alloying elements and external conditions, namely temperature and applied force.

The two basic modes of deformation are dislocation slip and mechanical twinning. In general, the slip system with the lowest critical resolved shear stress (i.e. the easiest to activate) is the $(0001)\langle 11 \overline{2} 0\rangle$ basal slip. The next to be activated is the $\{10 \overline{1} 0\}\langle 11 \overline{2} 0\rangle$ prismatic slip [3]. The above mentioned mechanisms provide only four independent slip systems and none of them provides deformation in the $\langle c\rangle$ direction, thus failing to meet the Von Mises criterion [4]. Possible mechanisms to supply the lacking system are the $\{11 \overline{2} 2\}\langle 11 \overline{2} 3\rangle 2^{\text {nd }}$ order pyramidal slip and deformation twinning. At room temperature, the $2^{\text {nd }}$ order pyramidal slip requires relatively high stress to be activated therefore in the grains oriented favorably for it, so called extension twinning (i.e. providing elongation along the c-axis) on the $\{10 \overline{1} 2\}$ twinning plane is likely to be activated [3]. Besides the mentioned twinning system, other observed twinning mechanisms in magnesium alloys are the $\{10 \overline{1} 1\}$ and $\{11 \overline{2} 1\}$ compression twinning and the $\{11 \overline{2} 2\}$ extension twinning [5]. 
The acoustic emission (AE) is defined by Heiple, Carpenter and Carr [6] as a transient elastic wave generated by the rapid release of energy within a material. $A E$ originates only from active defects of materials, for the purposes of this work namely nucleation of twins and avalanche-like movement of dislocations. The continuous signal resulting from the movement of dislocations can be detected only if enough dislocations are moving quickly and over a sufficient distance. The noncontinuous signal is typically (neglecting the nucleation and propagation of cracks in the final stages of deformation) caused by nucleation of twins. The growth of twins on the other hand, is too slow to be detected by AE [6-8]. In this work, the classical (so called hit-based) evaluation of the $A E$ events will be employed. The AE event is defined by various parameters (e. g. threshold level, duration, counts). The acquired data are then systematically evaluated and certain parameters (i.e. amplitude, count rate, energy rate) are examined to reveal the activated deformation mechanisms. This approach has been successfully applied by other authors (e.g. $[9,10])$.

\section{MATERIAL AND EXPERIMENTAL METHODS}

The deformation tests were performed on the commercial AZ31 rolled sheet ( $3 w t \% A l, 0.8 w t \% Z n, 0.2 w t \%$ $\mathrm{Mn}$ ) with a typical strong basal texture in the ND direction (Figure 1). Samples of three different orientations with respect to the initial texture - rolling direction (RD), normal direction (ND) and $45^{\circ}$ (between RD and ND, further on denoted 45) were cut out from the sheet. The dimensions of samples for compressive tests were 10 $\mathrm{mm} \times 6.5 \mathrm{~mm} \times 6.5 \mathrm{~mm}$, whereas the dimensions of the active area of the samples for tensile tests were $6 \mathrm{~mm}$ $\times 3 \mathrm{~mm} \times 2 \mathrm{~mm}$.

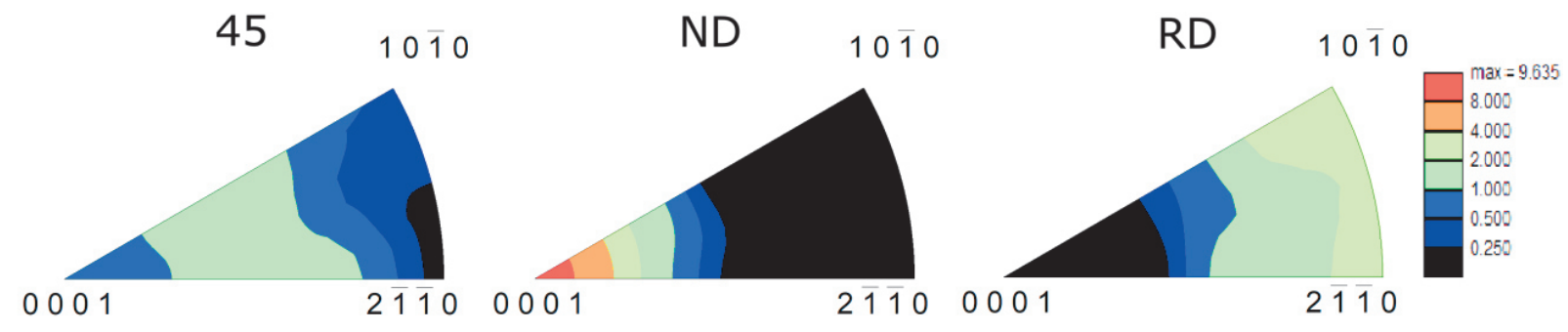

Figure 1 Inverse pole figure of the 45, ND and RD samples

The texture of the RD samples is favorably oriented for the prismatic slip and for the $\{10 \overline{1} 2\}\langle 10 \overline{1} 1\rangle$ extension twinning in compression. The 45 samples are favorably oriented for basal slip. The preferred slip system for the ND samples is the $2^{\text {nd }}$ order pyramidal slip and it is also favorably oriented for twinning in tension [11].

All deformation tests were performed at room temperature and with the initial strain rate of $10^{-3} \mathrm{~s}^{-1}$. Concurrently with the deformation tests, the $A E$ signal was recorded. For measuring the AE signal, the Physical Acoustics Corporation (PAC) PCl-2 device was used. To record the broad AE spectra, we employed the PAC PICO AE sensor. The sampling rate of recording was set to $5 \mathrm{MHz}$ and the AE signal was preamplified by the PAC 2/4/6 preamplifier with a $40 \mathrm{~dB}$ gain. Microstructure investigation of the samples deformed to the selected strains (i. e. $1 \%$ plastic strain in compression and $1 \%, 5 \%$ and $10 \%$ plastic strain in tension) was performed by electron backscattered diffraction (EBSD) with the EDAX EBSD camera installed in the ZEISS Auriga Compact scanning electron microscope. Samples for EBSD were mechanically ground down to $0.25 \mu \mathrm{m}$ diamond paste followed by ion-polishing by Leica EM RES102.

\section{RESULTS AND DISCUSSION}

The deformation curves obtained from the compressive and tensile tests are shown in Figure 2. For each curve, its yield point is marked. Corresponding values of yield and ultimate strengths are shown in Table 1. In compression, the curves of 45 and RD samples exhibit sigmoidal shape (so-called S-shape) typical for deformation mediated by the $\{10 \overline{1} 2\}\langle 10 \overline{1} 1\rangle$ extension twinning [12], whereas the ND curve is convex. The 
curves in tension exhibit opposite evolution, i.e. curves of the ND and 45 samples are sigmoidal and RD is convex. The values of yield strength (Table 1) are significantly lower for the samples oriented favorably for twinning in both compression and tension. This is caused by the necessity to activate the $2^{\text {nd }}$ order pyramidal slip in the samples oriented unfavorably for extension twinning in order to achieve homogenous plastic deformation.

\section{Compression}

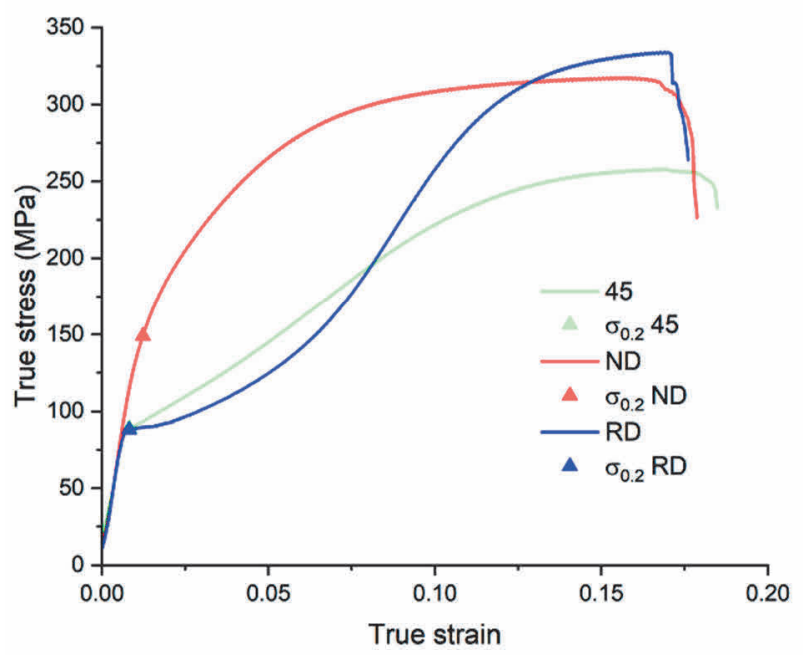

Tension

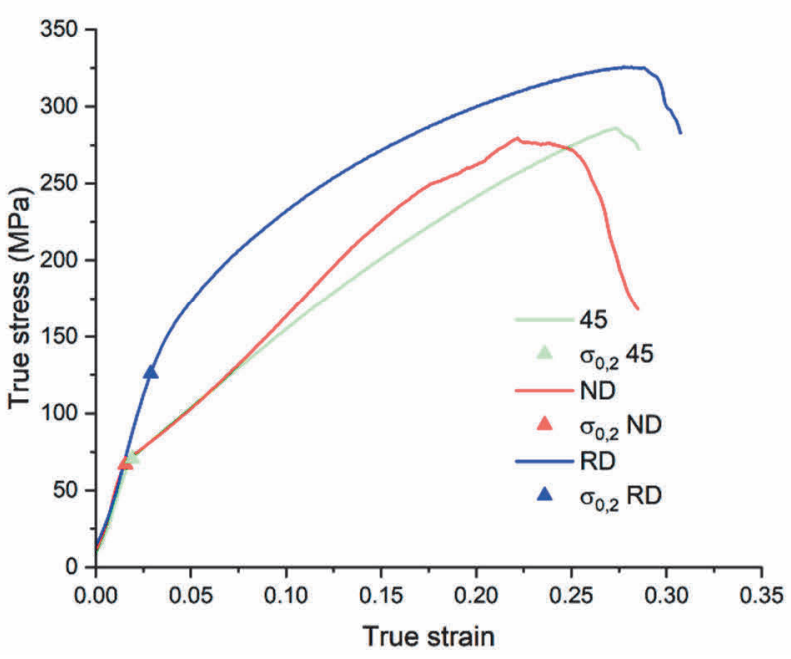

Figure 2 Deformation curves in compression and tension

Table 1 Yield stress and maximal stress for all orientations during tensile and compressive deformation

\begin{tabular}{|c|l|l|c|l|c|c|}
\hline \multirow{2}{*}{} & \multicolumn{2}{|c|}{45} & \multicolumn{2}{c|}{$\mathrm{ND}$} & \multicolumn{2}{c|}{ RD } \\
\cline { 2 - 7 } & $\sigma_{0.2}(\mathrm{MPa})$ & $\sigma_{\max }(\mathrm{MPa})$ & $\sigma_{0.2}(\mathrm{MPa})$ & $\sigma_{\max }(\mathrm{MPa})$ & $\sigma_{0.2}(\mathrm{MPa})$ & $\sigma_{\max }(\mathrm{MPa})$ \\
\hline Compression & $89 \pm 3$ & $258 \pm 8$ & $149 \pm 4$ & $317 \pm 10$ & $88 \pm 3$ & $334 \pm 10$ \\
\hline Tension & $71 \pm 2$ & $286 \pm 9$ & $67 \pm 2$ & $279 \pm 8$ & $126 \pm 4$ & $326 \pm 10$ \\
\hline
\end{tabular}

The count rate (i.e. number of oscillations exceeding the threshold level per second) and energy rate (the area under the signal envelope per second) of $\mathrm{AE}$ as a function of true strain is shown in Figure 3 (compression) and Figure 4 (tension) together with corresponding deformation curves. All of the samples exhibited the maximum AE energy and count rate around the yield point and the response was more pronounced for the samples oriented favorably for extension twinning (45 and RD samples in compression, 45 and ND samples in tension), which is consistent with the fact that the energy of $A E$ is typically higher for twin nucleation than for the dislocation slip [8]. There is a significant difference between the evolution of the AE response between compressive and tensile tests.

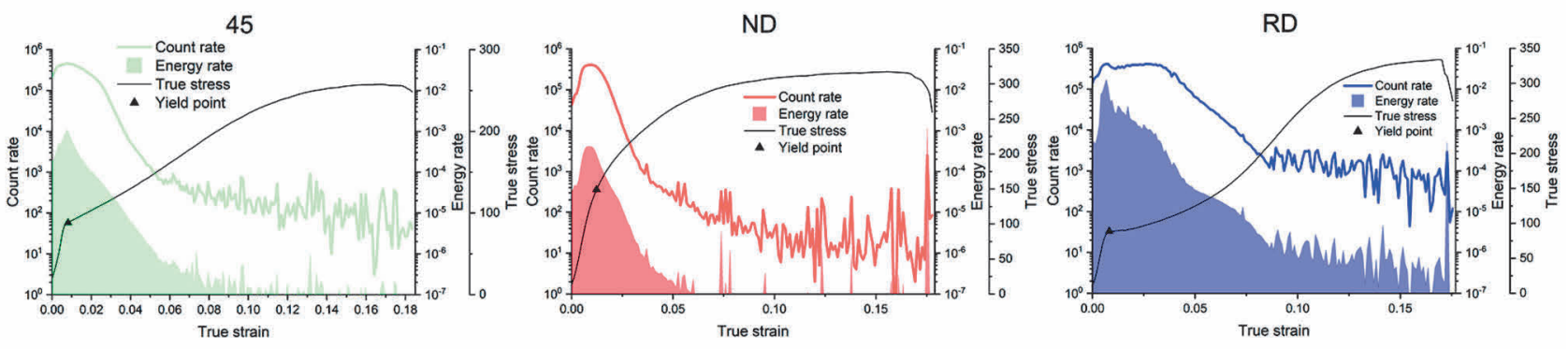

Figure $3 \mathrm{AE}$ count rate and energy rate in compression 
During compression, the count rate and energy rate tend to diminish shortly after reaching its peak close to the yield point. On the contrary, during tensile tests, the count and energy rate decline in a more gradual manner. A possible explanation for this phenomenon is that during compression, most of the $\{10 \overline{1} 2\}\langle 10 \overline{1} 1\rangle$ extension twins nucleate around the yield point and during further plastic deformation they grow in size, which is too slow process to be detected by AE [7, 8]. During tensile deformation however, new twins nucleate even at further stages of plastic deformation, which was also observed by other authors [13]. In order to confirm these assumptions, the follow-up microstructure observations of the deformed samples were performed, as shown in Figures 5 to 8.

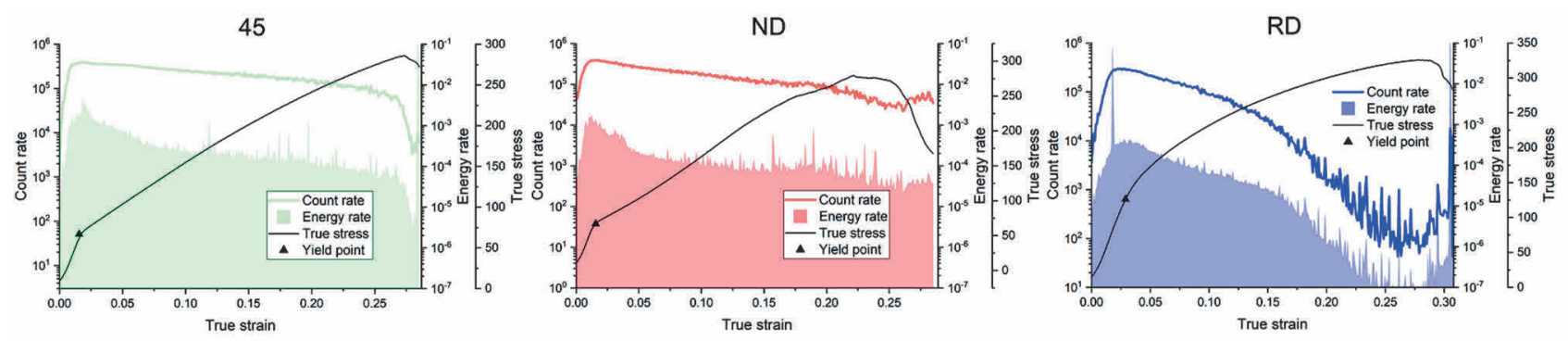

Figure $4 \mathrm{AE}$ count rate and energy rate in tension

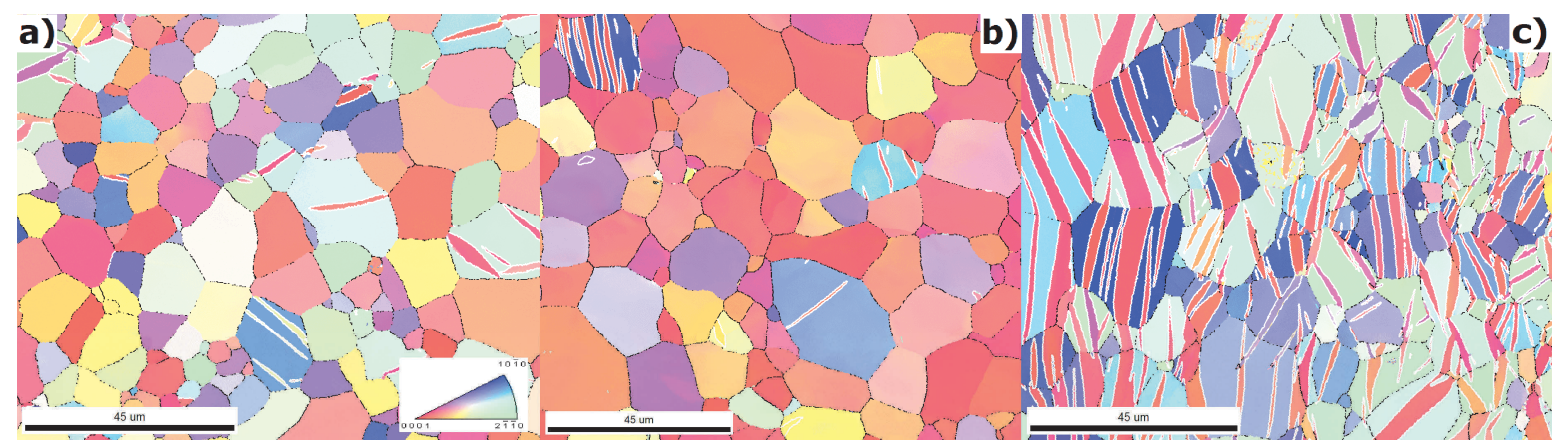

Figure 5 Microstructure of a) 45, b) ND, c) RD samples deformed in compression up to $1 \%$ plastic strain. Deformation was applied along the horizontal axis

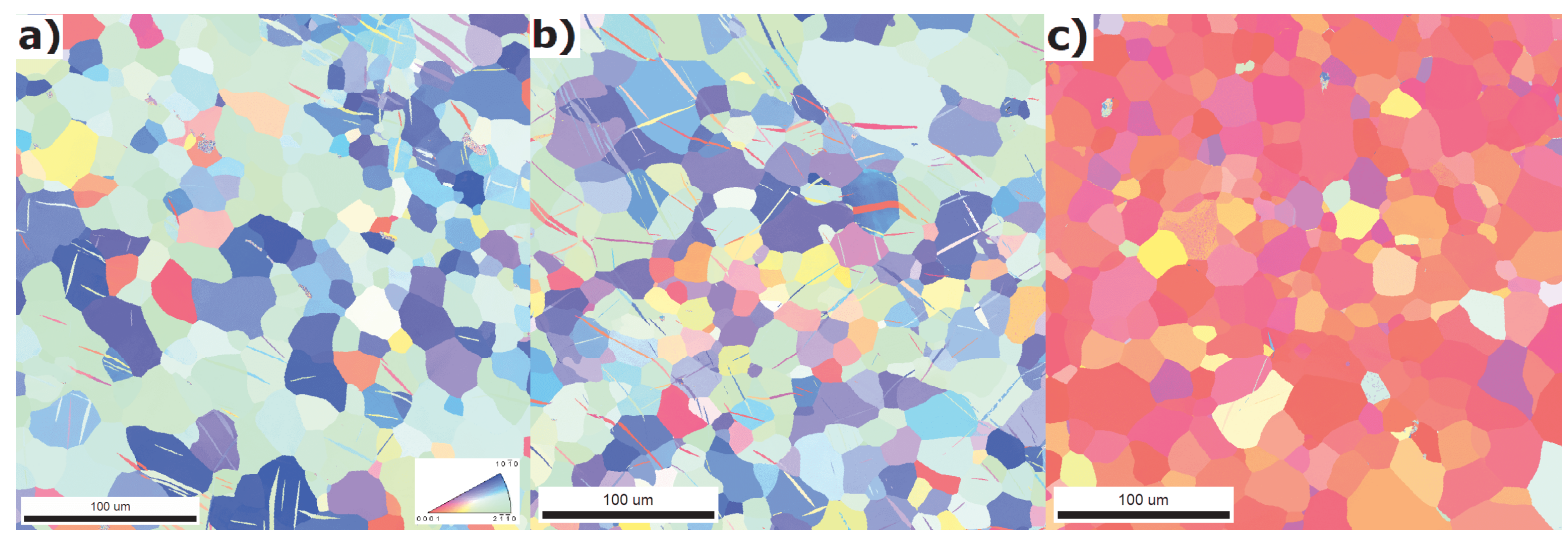

Figure 6 Microstructure of a) 45, b) ND, c) RD samples deformed in tension up to $1 \%$ plastic strain. Deformation was applied along the horizontal axis.

The microstructure of RD sample deformed in compression up to $1 \%$ plastic strain (Figure $\mathbf{5 c}$ ) exhibits high amount of extension twins penetrating grain boundaries (as a consequence of stress field adjacent to the twin [14]). The samples 45 and ND exhibit only small amount of highly twinned grains. The samples 45 and ND 
deformed in tension up to $1 \%$ plastic strain exhibit a number of thin twins, whereas the microstructure of the $\mathrm{RD}$ sample unfavorably oriented for twinning does not exhibit any extension twinning. These results are in good agreement with the AE data. Figure 7, depicting microstructure of samples deformed up to $5 \%$ plastic strain in tension reveals that the 45 sample contains numerous newly nucleated and still rather thin twins. Newly nucleated extension twins can also be found in the ND sample, while the RD sample retains its more homogenous microstructure with dominant dislocation slip character of deformation. Finally, Figure 8 shows heavily deformed microstructure of samples deformed up to $10 \%$ plastic strain in tension, where all deformation mechanisms including double twinning are activated in all samples. Furthermore, twin thickening takes place and dislocation mean free path is reduced as a consequence of new twin boundaries and increasing dislocation density at these later stages of deformation. These processes, in turn, result in the diminishing AE activity, as was documented in Figure 4.

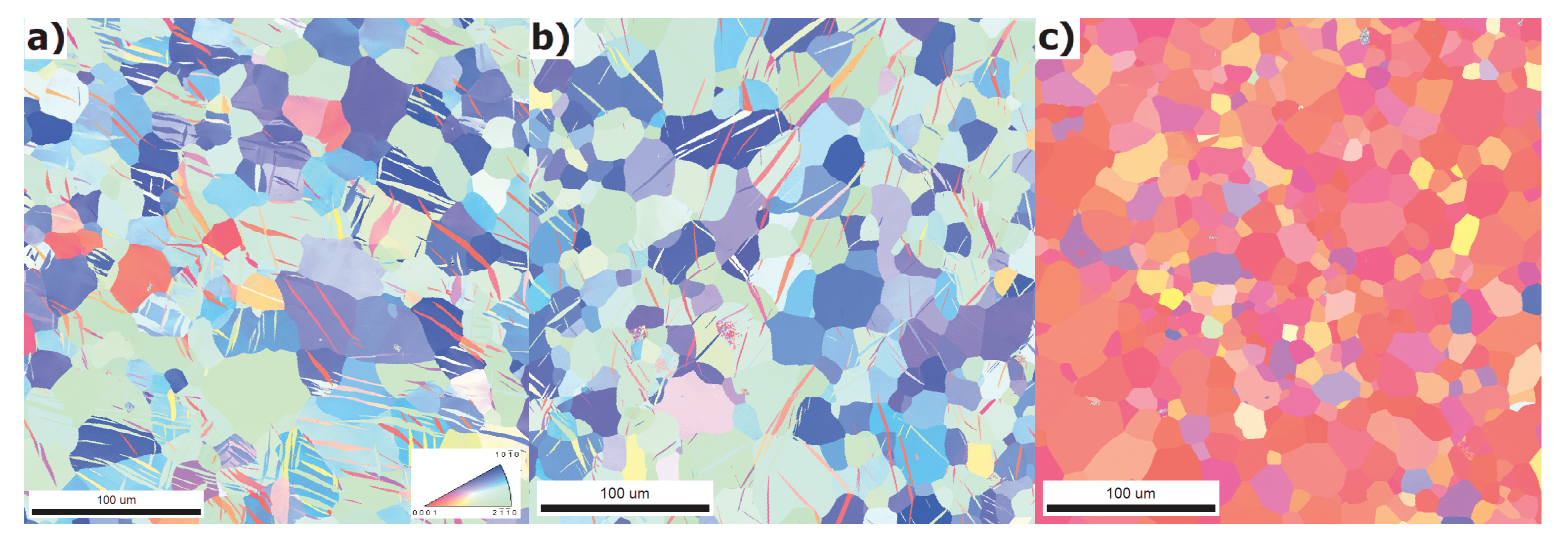

Figure 7 Microstructure of a) 45, b) ND, c) RD samples deformed in tension up to $5 \%$ plastic strain. Deformation was applied along horizontal axis.

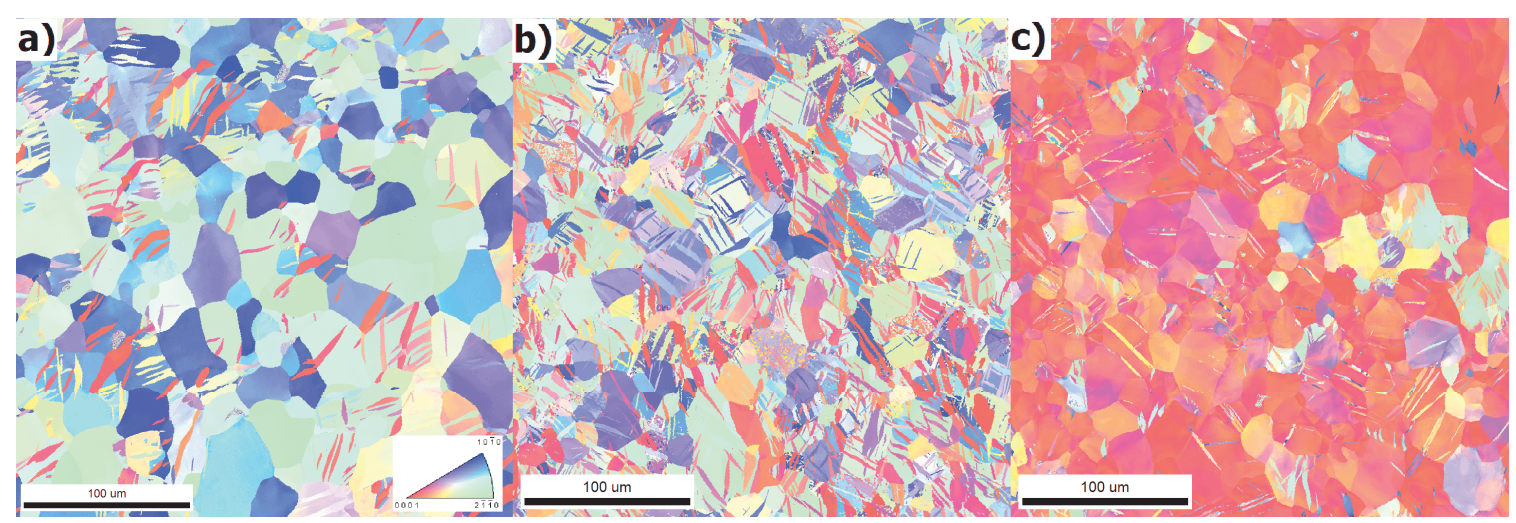

Figure 8 Microstructure of a) 45, b) ND, c) RD samples deformed in tension up to $10 \%$ plastic strain. Deformation was applied along horizontal axis.

\section{CONCLUSION}

The deformation tests along with the microstructural analysis revealed a significant dependency of activated deformation mechanisms on the orientation of samples and loading direction with respect to initial texture. Extension twinning plays an important role in RD and 45 samples in compression and in ND and 45 samples in tension. The measured yield stresses of the favorably oriented samples for extension twinning are significantly lower. An asymmetry in the evolution of AE response between compressive and tensile tests was observed and explained in terms of different evolution of twinned area in compressive and tensile samples. 


\section{ACKNOWLEDGEMENTS}

\section{The authors are grateful for the financial support of the Czech Science Foundation under the} contract 19-00270S.

\section{M.K. gratefully acknowledges financial support from the Operational Programme Research, Development and Education, The Ministry of Education, Youth and Sports (OP RDE, MEYS), grant No. CZ.02.1.01/0.0/0.0/16_013/0001794.}

\section{REFERENCES}

[1] MORDIKE, B.L. and EBBERT, T. Magnesium properties - application - potential. Materials Science and Engineering: A. 2001. vol. 302, iss. 1, pp. 37-45. DOl: https://doi.org/10.1016/S0921-5903(00)01351-4

[2] GUPTA, M. and NAI, S.L.M. Magnesium, Magnesium Alloys and Magnesium Composites. John Wiley \& Sons, 2011. ISBN 978-0-470-49417-2

[3] AGNEW, S.R. and DUYGULU, O. Plastic anisotropy and the role of non-basal slip in magnesium alloy AZ31B. International Journal of Plasticity. 2005. vol. 21, iss. 6, pp. 1161-1193.

[4] MISES, R. von. Mechanik der Plastichen Formänderung von Kristallen. ZAMM - Zeitschrift für Angewandte Mathematik und Mechanik. 1928. vol. 8, iss. 3, pp. 161-185 DOI: https://doi.org/10.1002/zamm.19280080302

[5] CHRISTIAN, J.W. and MAHAJAN, S. Deformation twinning. Progress in Materials Science. 1995. vol. 39, iss. 1-2, pp. 1-157. DOI: https://doi.org/10.1016/0079-6425(94)00007-7

[6] HEIPLE, C.R., CARPENTER, S.H. and CARR, M.J. Acoustic emission from dislocation motion in precipitationstrengthened alloys. Metal Science. 1981. vol. 15, iss. 11-12, pp. 587-597.

[7] HEIPLE, C.R. and CARPENTER, S.H. Acoustic Emission Produced by Deformation of Metals and Alloys - A Review: Part I. Journal of Acoustic Emission. 1987. vol. 6, iss. 2, pp. 177-204.

[8] HEIPLE, C.R. and CARPENTER, S.H. Acoustic Emission Produced by Deformation of Metals and Alloys - A Review: Part II. Journal of Acoustic Emission. 1987. vol. 6, iss. 4, pp. 215-237.

[9] DOBROŇ, P., BOHLEN, J., CHMELÍK, F., LUKÁČ, P., LETZIG, D., and KAINER, K.U. Acoustic emission during stress relaxation of pure magnesium and AZ magnesium alloys. Materials Science and Engineering A. 2007. vol. 462, iss. 1-2, pp. 307-310. DOI: 10.1016/j.msea.2005.12.111

[10] CHMELÍK, F., KLOSE, F.B., DIERKE, H., SACHL, J., NEUHAUSER, H., and LUKÁČ, P. Investigating the Portevin-Le Chatelier effect in strain rate and stress rate controlled tests by the acoustic emission and laser extensometry techniques. Materials Science and Engineering a-Structural Materials Properties Microstructure and Processing. 2007. vol. 462, iss. 1-2, pp. 53-60. DOI: https://doi.org/10.1016/j.msea.2006.01.169

[11] ČAPEK, J., KNAPEK, M., MINÁRIK, P., DITTRICH, J. and MÁTHIS, K. Characterization of deformation mechanisms in Mg alloys by advanced acoustic emission methods. Metals. 2018. vol. 8, iss. 8, pp. 644-655.

[12] PRASAD, K. E., LI, B., DIXIT, N., SHAFFER, M., MATHAUDHU, S. N. and RAMESH, K. T. The dynamic flow and failure behavior of magnesium and magnesium alloys. JOM. 2014. vol. 66, iss. 2, pp. 291-304.

[13] MÁTHIS, K., ČAPEK, J., ZDRAŽILOVÁ, Z. and TROJANOVÁ, Z. Investigation of tension-compression assymetry of magnesium by use of the acoustic emission technique.Materials Science and Engineering: A. 2011. vol. 528, iss. 18, pp. 5904 - 5907. DOI: https://doi.org/10.1016/j.msea.2011.03.114

[14] ŠIŠKA, F., STRATIL, L., Č́Ž̌EK, J., GHADERI, A. and BARNETT, M. Numerical analysis of twin thickening process in magnesium alloys. Acta Materialia. 2017. vol. 124, pp. 9-16. 